\title{
Semen Quality and Fertilizing Ability of Roosters Semen Diluted with Quail Egg-yolk Supplemented with Polar and Non Polar Dried Garlic Extracts
}

\author{
A. S. Balogun ${ }^{1,2^{\star}}$, O. A. Jimoh ${ }^{3}$, T. A. Olayiwola ${ }^{1}$ and Z. Y. Abubakar ${ }^{1}$ \\ ${ }^{1}$ Department of Animal Production Technology, Oyo State College of Agriculture and Technology, \\ P.M.B. 10, Igboora, Nigeria. \\ ${ }^{2}$ Department of Animal Breeding and Genetics, Guru Angad Dev Veterinary and Animal Sciences \\ University, Ludhiana, Punjab, India. \\ ${ }^{3}$ Department of Agricultural Technology, Federal Polytechnic Ado-Ekiti, Nigeria.
}

\begin{abstract}
Authors' contributions
This work was carried out in collaboration within the authors. Author ASB designed the study, performed the field, laboratory work and statistical analysis and wrote the first draft. Author OAJ perfected the protocol and methodology and wrote final draft of the manuscript. Authors TAO and ZYA were involved with field work and laboratory analysis. All authors read and approved the final manuscript.

\section{Article Information}

DOI: $10.9734 / J A B B / 2017 / 32395$

Editor(s):

(1) Dr. Csilla Tothova, Clinic for Ruminants, University of Veterinary Medicine and Pharmacy in Kosice, Slovak Republic. (2) Prof. Margaret Tzaphlidou, Department of Medical Physics, School of Health Sciences, loannina University, Greece. (3) Dr. James W. Lee, Department of Chemistry and Biochemistry, Old Dominion University, USA.

1) Kampon Kaeoket, Mahidol University, Thalar: Reviewers: (2) Dinithi Peiris, University of Sri Jayewardenepura, Sri Lanka. (3) Sellami Afifa, Medical School Sfax, Tunisia. Complete Peer review History: http://www.sciencedomain.org/review-history/19322
\end{abstract}

Original Research Article

Received $24^{\text {th }}$ February 2017 Accepted $13^{\text {th }}$ May 2017 Published $3^{\text {rd }}$ June 2017

\section{ABSTRACT}

Aim: This study was designed to assess the potentials of dry garlic extracts to improve rooster semen quality for on-farm hen insemination.

Study Design: Completely randomized design in a factorial arrangement.

Place and Duration of Study: Poultry unit of the Teaching and Research Farm, Oyo State College of Agriculture and Technology Igboora, Oyo State, Nigeria. The study lasted for eight weeks.

Methodology: Dry garlic was processed to obtain its aqueous, ethanolic and methanolic extracts using standard procedures. The extracts were assessed for percentage free radicals scavenging ability and supplemented in egg-yolk citrate extender. The semen parts were randomly allotted to 
three extender containing different extracts in different concentrations and eight nested inclusion. The extender was diluted with the semen in ratio 2:1. The samples were assessed for semen quality Parameters: $\mathrm{pH}$, mass activities, motility, livability and sperm concentration. The extended semen samples that possess sperm motility above $50 \%$ were further considered for artificial insemination to assess in vivo fertilizing ability of the sperm cells. A total number of 120 hens were allocated randomly to each treatment at 5 hens/treatment. The hens were everted and extended semen was deposited into the intra vagina of the hens. The hens were inseminated twice weekly in the evening for a period of 6 weeks.

Results: Aqueous garlic extracts performed better than its associate when supplemented into Quail egg-yolk citrate extenders for semen quality evaluation, evident by better mass activities, motility and viability across the inclusion levels. Higher fertility and hatchability was recorded across the treatments (3-6) with aqueous garlic extracts comparable to unextended semen performance.

Conclusion: Aqueous garlic extract supplemented in quail egg yolk used as a poultry semen diluents, exhibited better antioxidant potential and has further elicited better sperm quality by enhancing in-vivo fertilizing potential of the sperm cells than the other two counterpart extracts.

Keywords: Garlic; In-vivo; extracts; extender; semen and fertility.

\section{INTRODUCTION}

Available, affordable, effective and standard diluents still remain the major problem faced by poultry breeders all over the world. Labor, feed and energy costs are forcing poultry breeders to consider more economical ways of maintaining gene pools [1]. One solution to reduce such costs is with the use of extended semen in poultry breeding industries. With diluted semen available from superior sires, poultry breeders will have the tool to increase genetic advancement per generation, gain a more precise evaluation of genetic improvement, allow optimum use of sires, and transfer of genetic material worldwide [1]. More advantages that may be derived from using fewer outstanding males breeders and obtaining better quality offspring from the use of superior sires will account for more than the cost of semen diluents [1]. However, high level of PUFAs (Polyunsaturated fatty acids) increases the susceptibility of cells to free radical attack and lipid peroxidation. It also appears that the 20: 4 n-6 and 22: 4 n-6 present in avian spermatozoa performs an essential function in promoting optimal spermatozoa motility, viability and fertilizing capacity, as marked reductions in the amounts of these fatty acids in spermatozoa as a result of lipid peroxidation are associated with impaired sperm number, motility, viability and fertilizing ability [2]. Therefore, antioxidant protection is a vital element in maintaining motility, viability, membrane integrity and fertilizing ability [3].

Antioxidants are believed to play a very important role in the body defence system against reactive oxygen species (ROS) or free radicals, which are harmful by-products generated during aerobic activity of normal cells. Increasing the level antioxidant is believed to assist in maintaining an adequate antioxidant status and therefore, the normal physiological function of living system.

The antioxidant properties of garlic and different garlic preparations are well documented [4]. Garlic (Allium sativum L.) and garlic constituents prepared by various means have been shown to have diverse biological activities, including anticarcinogenic, antiatherosclerotic, antithrombotic, antimicrobial, antioxidant, antiinflammatory and various other biological actions [5]. Potential antioxidant properties of garlic are as a result of presence of phenolic and flavonoids fractions [6]. Extracts of garlic contain phytoantioxidant that prevent oxidant damage. These include unique water-soluble organosulfur compounds, lipid-soluble organosulfur components and flavonoids, notably allixin and selenium [7]. Diallyl tetrasulphide is the bioactive organosulphur component of garlic, which have antioxidant effects [8]. Quail egg also contained significantly more phosphatidylcholine, less phosphatidylethanolamine, and a smaller ratio of polyunsaturated to saturated fatty acids [9].

Although a lot of poultry diluents has been produced in the past, howerever, up till the present moment non has been globally standardize for use, moreover majority are produce solely from synthetic chemicals which are considered being expensive and not readily available for the poultry breeders. In the present scenario, there is an urgent and continuous need for exploration and development of affordable 
and effective organic based poultry diluents. Hence the attention has been focused on biological active substance of plant and animal species for use in poultry breeding industries. This experiment therefore harnessed the combine potentials of quail egg-yolk and dried garlic different extracts as extender for roosters semen.

\section{MATERIALS AND METHODS}

The study was carried out at Teaching and Research Farm, Oyo State College of Agriculture and Technology Igboora, Oyo State, Nigeria. The study was approved by our institutional committee on the care and use of animals for experiment.

The fresh garlic was purchased from Bodija market at Ibadan, Oyo State. The proximate analysis of the fresh garlic samples was carried out according to the method of [10].

\subsection{Garlic Extraction}

The clove and bulb were separated, the dried garlic was crushed with a blender. Ethanol and methanol (Sigma Aldrich) and double distilled water. $4 \mathrm{~g}$ of fresh garlic sample was weighed in triplicate and loaded into sterile container and the extraction agents were added, in ratio 1:4 (20 g garlic to $80 \mathrm{ml}$ extraction agents). It was soaked for 72 hours and filtrate was obtained from the residues. Rotary evaporator was further used to separate the volatile extraction agents, to obtain a concentrated garlic extracts samples (95\%).

DPPH (Diphenyl-2-picryl-hydrazylhydrate) assay (free radicals scavenging ability) was carried out on extracts according to the method described by [11].

\subsection{Preparation of Extenders}

Freshly laid hen eggs were collected, and the egg shells were sterilized with $75 \%$ alcohol. The eggs were carefully broken at the broader end with forcep and the separation of yolk from albumen was done using a filter paper. The egg yolk and sodium citrate buffer solution were added and mixed using magnetic stirrer. Garlic extracts was added at $1 \%, 2 \%, 3 \%, 4 \%, 5 \%$, and $6 \%$ levels each for aqueous, ethanol and methanol. The mixture was centrifuged at 5000 rpm for 5 minutes for homogeneous mixing of the samples.

\subsection{Experimental Animals Procurement and Management}

20 Marshal roosters and 120 hens were procured from a reputable breeding farm in Oyo State and were housed in battery cage containing one (1) rooster per cell and two (2) hens per cell. The birds were managed based on breeders' recommendations (Marshal Management guide).

\subsection{Experimental Design}

Semen ejaculate pool of 20 Marshal roosters of 40 weeks old, were collected and divided into twenty equal parts. The semen parts were randomly allotted to three extract and eight nested inclusion levels in a completely randomized design in a factorial arrangement. The treatments were diluted with the constituted extenders in ratio $1: 2$. To obtained $\left(200 \times 10^{9}\right.$ million)

Factor A: Extraction agents:
1. Aqueous
2. Methanol
3. Ethanol

Factor B: Inclusion Levels:

$$
\text { 1\% (T3), 2\% (T4), 3\% (T5), 4\% (T6), 5\% (T7) }
$$
and $6 \%(\mathrm{~T} 8)$

Controls:

1. Unextended Semen (T1)

2. Egg Yolk Extender (T2)

Each treatment was replicated three times.

\subsection{Semen Collection}

The semen was collected twice a week throughout the duration of the study by dorsalabdominal massage method. Caution was taken to avoid any contamination of semen with cloacal products such as faeces.

\subsection{Semen Processing and Evaluation}

Yellow and abnormal semen samples were discarded. The ejaculates of 20 cocks were individually evaluated using colour, constitency and volume (for individual cock). The semen pooled was accessed for their quality. 


\subsection{Extension of Semen with Extenders and Evaluation}

The pooled semen were allotted as described earlier and diluted with extender dose. Diluted samples were mixed gently to allow equilibration and semen assessment took place immediately. Dilution rate is 1:2, (semen:diluents). Extended semen according to treatments was evaluated for motility, concentration, livability and semen $\mathrm{pH}$.

Spermatozoa motility was evaluated using a phase-contrast microscope at $\times 400$ magnification and is expressed as percentage of motile spermatozoa before and after holding. For the evaluation of motility, about $10 \mu \mathrm{l}$ drop of the 1:2 diluted semen was placed on a microscope slide and covered with a coverslip. For each sample, at least five microscopic fields were observed. Only samples that showed high motility $(>80 \%)$ were used for on-farm insemination.

Sperm concentration (two replicates) is determined using Neubaurhaemocytometer (TH100; Hecht-Assistant, Sondheim, Germany) and expressed as spermatozoa $\times 10^{9} / \mathrm{ml}$.

Livability was done by placing a drop of semen on a glass slide, one drop of eosin-nigrosin stain was added and mixed gently, it was later smeared on a slide, air-dried and viewed under the microscope at magnification of $\times 400$.

The $\mathrm{pH}$ of un-extended semen and extended semen was measured using electronic $\mathrm{pH}$ meter.

\subsection{Insemination of the Hen}

Hens were inseminated immediately after the assessment. And the insemination doses were $0.1 \mathrm{ml}$ per hen $\left(200^{*} 10^{6}\right)$

\subsection{Incubated Egg Fertility Assessment}

The fertilizing ability of spermatozoa is assessed by intravaginal insemination of five females per experimental group making a total 120 hens. Hens were inseminated with approximately $200 x$ $10^{6}$ viable spermatozoa. Eggs were collected daily, stored and incubated weekly. The fertility percentage (fertile/incubated eggs $\times 100$ ) was determined by candling on the 18th day of incubation. Using the formulae below:

$$
\text { Fertility (\%) }=\frac{\text { no of fertile eggs }}{\text { total no eggs set }} \times 100
$$

\subsection{Incubated Egg Hatchability Assessment}

At every $14^{\text {th }}$ day of incubation eggs were transferred from the setter to the hatcher through the use of hatching baskets for the last 7 days were incubation and hatching take place hatching percentage will be determined by hatching of fertile eggs about 21 days after start of incubation. Numbers of chicks hatched will be counted and percentage hatchability will be calculated using the formular below:

$$
\begin{aligned}
& \text { Hatchability of fertile eggs }(\%)= \\
& \frac{\text { no of egg hatched }}{\text { total no of fertile eggs }} \times 100 \\
& \text { Hatchability of eggs set }(\%)= \\
& \frac{\text { no of egg hatched }}{\text { total no of eggs set }} \times 100
\end{aligned}
$$

\subsection{Statistical Analysis}

The data obtained were subjected to analysis of variance (ANOVA) at $P=0.05$. Significant means were separated using DMRT (Ducan multiple range test) using SAS (2001) software package.

\section{RESULTS AND DISCUSSION}

The result of proximate analysis of dried garlic was presented in Table 1 . The proximate analysis of fresh garlic reveals crude protein $17.76 \%$, crude fibre $2.42 \%$, ether extracts $2.39 \%$, ash $2.39 \%$ and dry matter $78.14 \%$.

Table 1. Proximate analysis of dried garlic

\begin{tabular}{ll}
\hline Treatment & Dry garlic \\
\hline Crude protein (\%) & 17.76 \\
Crude fibre (\%) & 2.42 \\
Ether extract (\%) & 2.39 \\
Ash (\%) & 2.39 \\
Dry matter (\%) & 78.14 \\
Moisture content (\%) & 21.87 \\
\hline
\end{tabular}

The results obtained on free radicals scavenging abilities of different dried garlic extracts were presented in Fig. 1. The percentage free radical scavenging abilities revealed that DGAQE (Dried garlic aqueous extract) had the highest value of $62.61 \%$, followed by DGEE (Dried garlic ethanolic extract) and DGME (Dried garlic methanolic extract) which had the values of $47.80 \%$ and $39.23 \%$ respectively. Convincingly DGAQE had the better ability to scavenge and 
mop the reactive oxygen species, Free radical scavenging abilities of different garlic samples is an indication that dried garlic antioxidant components can be best extracted with non polar solvent, and expected to be capable of utilizing its full potential effects on free radicals contained in semen. This may serve as an indication that majority of the important phytoantioxidant component essential for free radical scavenging abilities are water soluble. [12] reported that water had affinity for phyto-antioxidant recovery from fresh garlic than its counterpart with it's peculiarities for scavenging free radicals. This also corroborate the findings of [13] who reported that Selecting the right solvent affects the amount and rate of polyphenols extracted. It is revealed from this result that non polar solvent is most appropriate extraction agent of choice when harnessing the garlic available and functional antioxidant properties as majority of these properties are water soluble.

The results obtained on effect of dry garlic (aqueous, ethanolic and methanolic) extracts on extended semen $\mathrm{pH}$ were presented in Fig. 2. The result of the egg yolk dried garlic aqueous extract extended semen indicated that $\mathrm{T} 1$ has the highest value of 6.05 and was significantly different from other treatments $(2,3,4,5,6,7$ and 8). Although treatments 2 to 7 were not significantly different $(P>0.05)$ from each other by with the values ranging between 5.95 to 5.88 , while T8 is the lowest value has 5.70 and was significantly different $(\mathrm{P}<0.05)$ to $\mathrm{T} 1$ and $\mathrm{T} 8$.

The results obtained on effect of dry garlic aqueous, ethanolic and methanolic extracts on extended semen sperm mass activities were presented in Fig. 3. The result of the egg yolk dried garlic aqeous extract extended semen indicated that T1, T2 and T4 had the same highest value of $100 \%$ and were significantly different $(\mathrm{P}<0.05)$ to $\mathrm{T} 3, \mathrm{~T} 5$ to T8 which had the same value of $80 \%$. While that of egg yolk dried garlic ethanolic extract extended semen shows that T1 and T2 have the same highest value of $100 \%$ and were significantly different $(P<0.05)$ from other treatments $3,4,5,6,7$ and 8 which had the values of $80,60,40,0,0,10$ respectively.

The result of egg yolk dried garlic methanolic extract extended semen indicate that $\mathrm{T} 1$ and $\mathrm{T} 2$ had the same percentage value of $100 \%$ for sperm mass activities, and was not significantly different $(P>0.05)$ to the value obtained for treatment 3 which had $80 \%$, but was significantly different $(P<0.05)$ to $T 4, T 5, T 6, T 7, T 8$ which had the values of $60 \%, 40 \%, 10 \%, 10 \%, 10 \%$ respectively, with T6, T7 and T8 also had same value of $10 \%$ and was significantly different $(P<0.05)$.

The results obtained on comparative antioxidant capacity of dry garlic aqueous, ethanolic and methanolic extracts on extended semen sperm motility were presented in Fig. 4. The result of the egg yolk dried garlic aqueous extract extended semen shows that treatment 1, 3 and 4 had the same and highest motility value of $95 \%$ but was significantly different $(P<0.05)$ to the values obtained for treatments T5 and T2 which had the values of $92.5 \%$ and $90 \%$ respectively. Also treatments 6,7 and 8 were not significantly different $(P>0.05)$ from each other which had the percentage values of $80,77.5$, and 75 respectively, but was significantly different (P>0.05) from treatment 1, 2, 3, 4 and 5 . The result of the egg yolk- ethanolic dried garlic extract extended semen indicated that $\mathrm{T} 1$ had the highest value of $100 \%$ follow by T2 with no significant different $(P<0.05)$ but was significantly different $(P>0.05)$ to all other treatments 3, 4, 5, 6,7 and 8 , while T3 and T4 had the same value of $77.5 \%$. Treatment 5 had the percentage value of 57.5 follow by T7, T6 and T8 having the value of $27.5,15$ and 7.5 with an obvious significant different $(P>0.05)$, except for treatments 6 and 8 with had no significant difference $(P>0.05)$.

The result of the egg yolk dried garlic methanolic extract extended semen shows that treatment 1 had the highest percentage motility value of $95 \%$ and was not significantly different $(P>0.05)$ to $T 2$, but was significantly different to values obtained for T3, T4, T5, T7, T8 and T6 which had the values as follow $90 \%, 70 \%, 62.5 \%, 45 \%, 25 \%$, $25 \%$ and $20 \%$ respectively, while T7 and T8 have the same value of $25 \%$.

Livability and sperm concentration showed no significant difference $(P>0.05)$ across the treatments.

Interestingly, the aqueous garlic extracts performed better than its associate when supplemented with the extender egg-yolk citrate extenders for semen characteristics evaluation. It has exhibited a very good mass activities, motility and viability across the inclusion levels with respect to its better antioxidant protections compared to the two other extracts which were capable to retain mass activities and motility required for insemination only up to $2 \%$ inclusion level. [3] reported that, antioxidant protection is a vital element in maintaining motility, viability, 
membrane integrity, and fertilizing ability. It was evident from this study that semen characteristics quality such as mass activities and motility were better in EYDG.AQE extended semen compare to the other two extenders formulated which are EYDG.ME and EYDG.EE. The significant performance of EYDG.AQE can be trace to the ability of DGAQE to properly scavenge free radicals in the semen samples, thereby making nutrient to be sufficiently available for the sperm cell activities throughout the period between dilution and assessment. Garlic is one antioxidant that defends against free radicals damage, thereby preserving the body's healthy functioning [14]. It was also reported that $\mathrm{GE}$ exerts antioxidant action by scavenging reactive oxygen species (ROS), enhancing the cellular antioxidant enzymes superoxide dismutase, catalase and glutathione peroxidase, and increasing glutathione in the cells [15].

In addition the drastically fall in percentage sperm motility and mass activities of the semen in EYDG.ME and EYDG.EE formulated extenders observed starting from particular levels of inclusions like $3 \%$, may be due to inability of the sperm cells to tolerate higher levels of inclusions of the two polar extracts included in the egg-yolk extender other than $1 \%$ and $2 \%$ levels, since it is assumed that the two extracts is highly concentrated with other components which may be harmful to sperm cells. These results corroborated the previous findings which reported that Garlic causes a dose-dependent increase in the percentage of empty seminiferous tubules, thereby altering spermatogenesis and reducing testosterone secretion [16].

It also conceivable that sperm concentration, percentage lives sperm and semen ph were favourable compare to the standard and the unextended semen irrespective of the different extracts and their concentrations in the extenders used for the experiment. It has been reported that unique water-soluble organosulfur compounds, lipid-soluble organosulfur components and flavonoids, are notably in allixin and selenium [7]. [17] also pointed out that antioxidant activity in seminal plasma and sperm is not high enough to prevent lipid peroxide damage after extension and in vitro storage, and that supplemental antioxidants could improve semen shelf life. $[18,19,20,3]$ who found that the addition of certain antioxidants (vitamins $A, C$ or E) to the avian semen diluents preserved motility, viability, morphology and fertilizing capacity of semen stored for different storage periods at 4$6^{\circ} \mathrm{C}$.

The results obtained on comparative antioxidant capacity of dry garlic aqueous, ethanolic and methanolic extracts on inseminated hens' fertility of eggs set were presented in Fig. 5. The result of the fertility record of hens inseminated with egg-yolk dried garlic aqueous extracts extended semen shows that treatments 1 and 7 were having the same and highest fertility percentage value of 80.0 , which was accompanied by treatments $8,3,6,2,5$ and 4 which had the values of $71.4 \%, 70.8 \%, 60.0 \%, 55.6 \%, 54.3 \%$ and $52.6 \%$ respectively.

The result of the fertility record of hens inseminated with egg-yolk dried garlic methanolic extracts extended semen showed that treatment 1 possessed the highest fertility record of $80.0 \%$, followed by treatments $4,5,2$ and 3 which had the values of $65.4 \%, 63.2 \%, 55.6 \%$ and $33.3 \%$ respectively.

The result of the fertility record of hens inseminated with egg-yolk dried garlic ethanolic extracts extended semen shows that treatment 1 possessed the highest percentage fertility record of $80.0 \%$, which was followed by treatments 3,4 , 5 and 2 , which had the percentage fertility values of $66.7 \%, 64.0 \%, 55.6 \%$ and 50.0 respectively.

The results obtained on comparative antioxidant capacity of dry garlic aqueous, ethanolic and methanolic extracts on inseminated hens hatchability of fertile eggs set were presented in Fig. 6. The hatchability record of fertile egg sets of hens inseminated with egg-yolk dried garlic aqueous extracts revealed that treatment 2 and 6 had $100.0 \%$ hatchability of fertile eggs set, which was followed by treatments $8,7,3,1,5$ and 4 which had the values of $93.3 \%, 91.67 \%, 88.24 \%$, $87.5 \%, 84.62 \%$ and $80.0 \%$ respectively.

The hatchability record of fertile egg sets of hens inseminated with egg-yolk dried garlic methanolic extracts shows that treatments 2 and 4 had the highest percentage hatchability of $100 \%$ and was accompanied by treatments 5, 3 and 1 which had the values of $92.9 \%, 90.0$ and 87.5 respectively.

The hatchability record of fertile egg sets of hens inseminated with egg-yolk dried garlic ethanol extracts revealed that treatments 2 and 3 had the highest percentage hatchability of $100.0 \%$ and was accompanied by treatments 1,5 and 4 which had the values of $87.5,83.3$ and 76.5 respectively. 
The results obtained on comparative antioxidant capacity of dry garlic aqueous, ethanolic and methanolic extracts on inseminated hens hatchability of eggs set were presented in Fig. 7 . The hatchability results of eggs set of hens inseminated with egg-yolk dried garlic aqueous extracts extended semen revealed that treatment 7 had the highest percentage egg set hatchability value of 73.3, although treatment 1 had a close hatchability value of 70.0 followed by treatment $8,3,6,2,5$ and 4 with the values of $66.7 \%$, $62.5 \%, 55.6 \%, 45.8 \%$ and $42.1 \%$ respectively.

The hatchability results of eggs set of hens inseminated with egg-yolk dried garlic methanolic extracts extended semen indicated that treatment 1 had the highest percentage egg set hatchability of $70.0 \%$, while treatments 2,4 and 5 which had the percentage eggs set hatchability ranging from 50.0 to $55.6 \%$, although treatment 3 had the lowest percentage egg set hatchability of $33.3 \%$.

The hatchability results of eggs set of hens inseminated with egg-yolk dried garlic ethanolic extracts extended semen indicated that Treatment 1 had the highest percentage hatchability egg sets value of $70.0 \%$, followed by treatment 4, 3, 2 and 5 which had the percentage hatchability egg set values of $64.0 \%, 60.0 \%$, $55.56 \%$ and $46.4 \%$ respectively.
Expectedly the higher fertility and hatchability recorded across the treatments (3-6) with AQGE compared to unextended semen gives clear indication that the results follow a similar pattern with that obtained from the free radical scavenging abilities of different extracts. Obviously the AQGE antioxidant potential had been best utilized in-vivo during the activities of the sperm cells inside the hen oviduct than the other two extracts. [21] concluded that reinforcement of semen extender with suitable additives is suggested to reduce oxidative damage during freeze-thawing of bull and buffalo spermatozoa, also in accordance with the previous findings of $[18,19,20,3]$ who found that the addition of certain antioxidants (vitamins A, C or $E)$ to the avian semen diluents preserved motility, viability, morphology and fertilizing capacity of semen stored for different storage periods at $4-6^{\circ} \mathrm{C}$.

It was noteworthy that the highest fertility observed in treatment 7 compare to the unextended semen in EYDGAQE extended semen was an indication that the best level of inclusion of DGAQE that will enhance a good fertility result is $5 \%$ inclusion level. Although this level may not be applicable to the two other eggyolk polar garlic extracts formulated extenders, but 1 and $2 \%$ inclusions of the other extracts will still give a satisfactory fertility result.

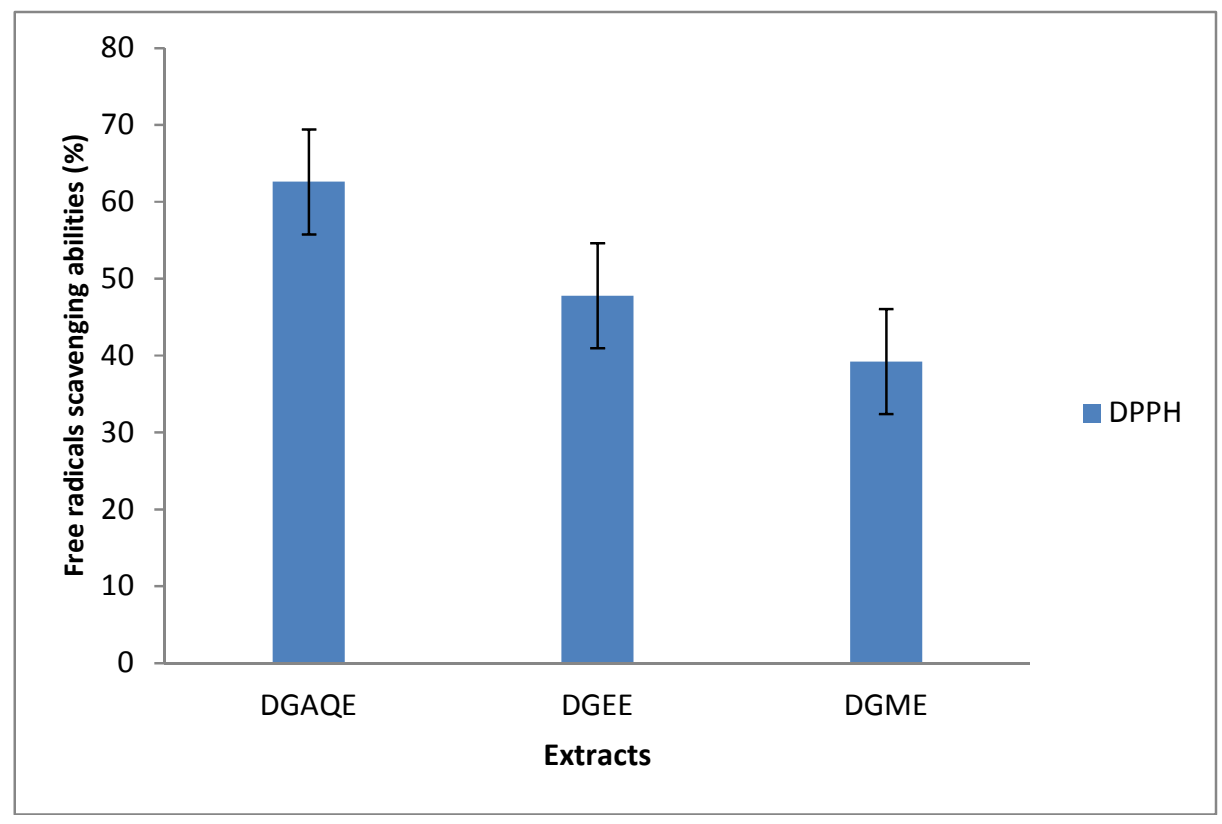

Fig. 1. Free radicals scavenging abilities (aqueous, ethanolic and methanolic) extracts DG.AQE - Dried Garlic Aqeous Extract; DG.EE - Dried Garlic Ethanlic Extract; DG.ME - Dried Garlic Methanolic Extract 


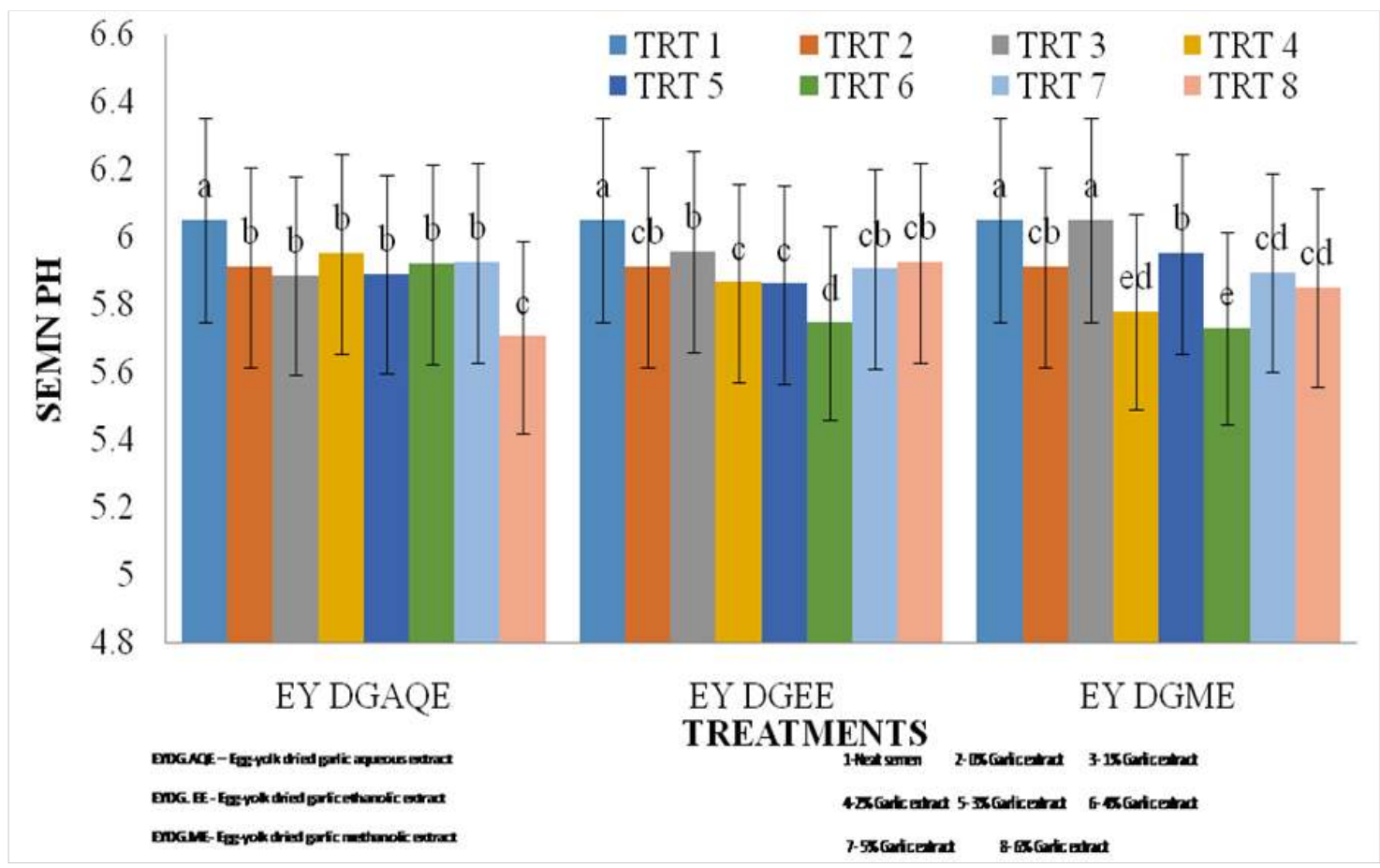

Fig. 2. Effect of dry garlic (aqueous, ethanolic and methanolic) extracts on extended semen pH

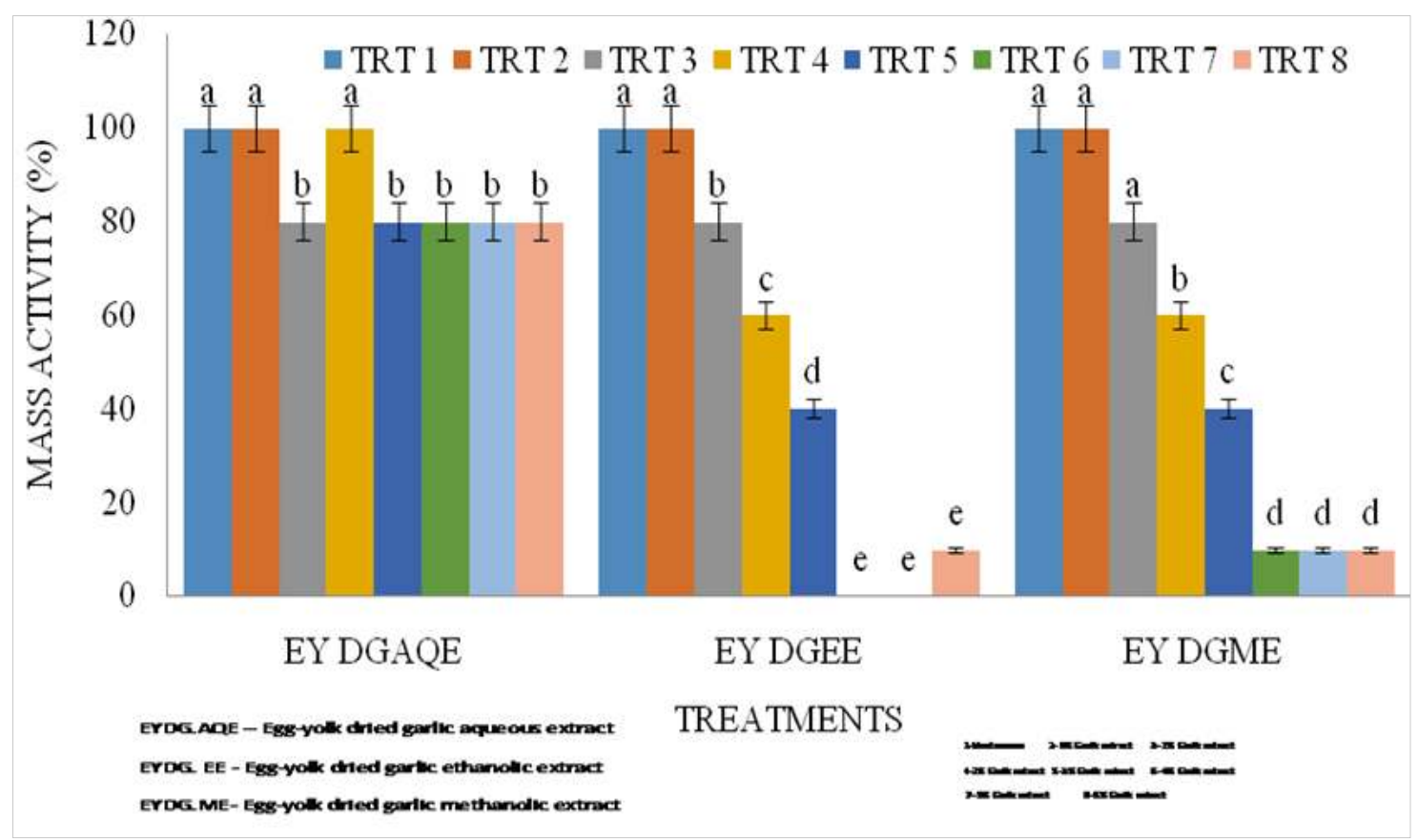

Fig. 3. Effect of dry garlic aqueous, ethanolic and methanolic extracts on extended semen sperm mass activities 


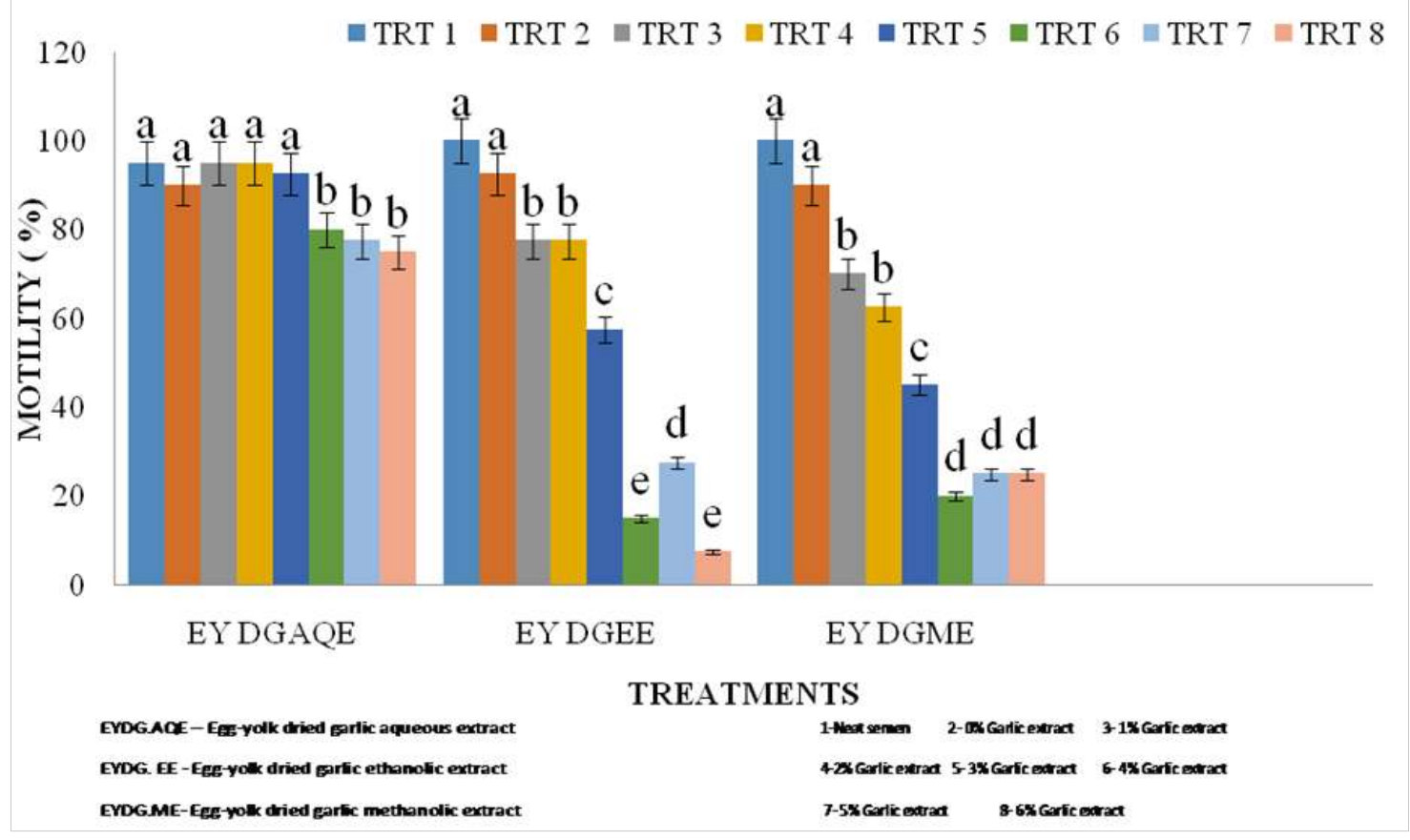

Fig. 4. Effect of dry garlic aqueous, ethanolic and methanolic extracts on extended semen sperm motility

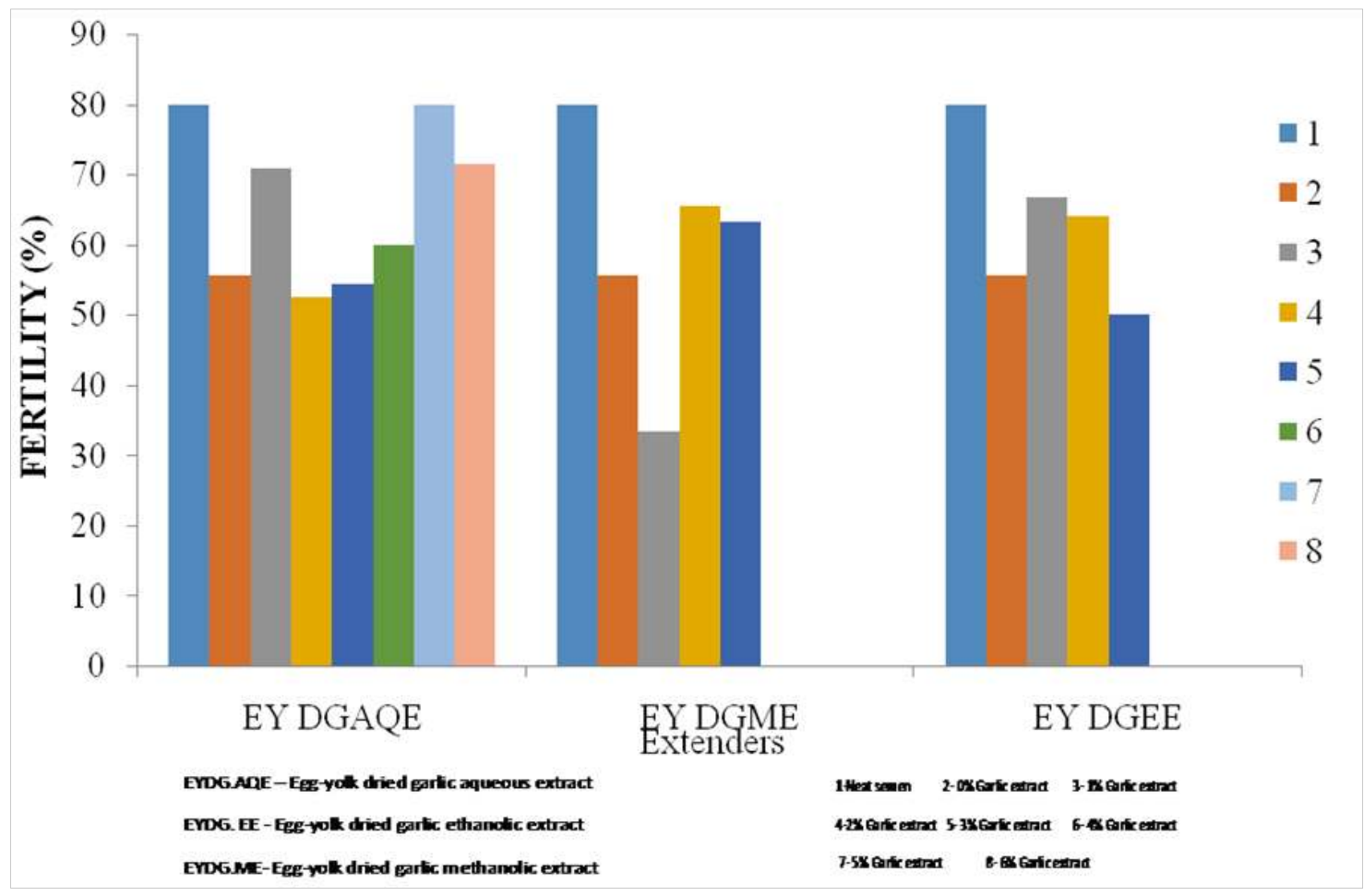

Fig. 5. Effect of dry garlic aqueous, ethanolic and methanolic extracts on inseminated hens' fertility of eggs set 


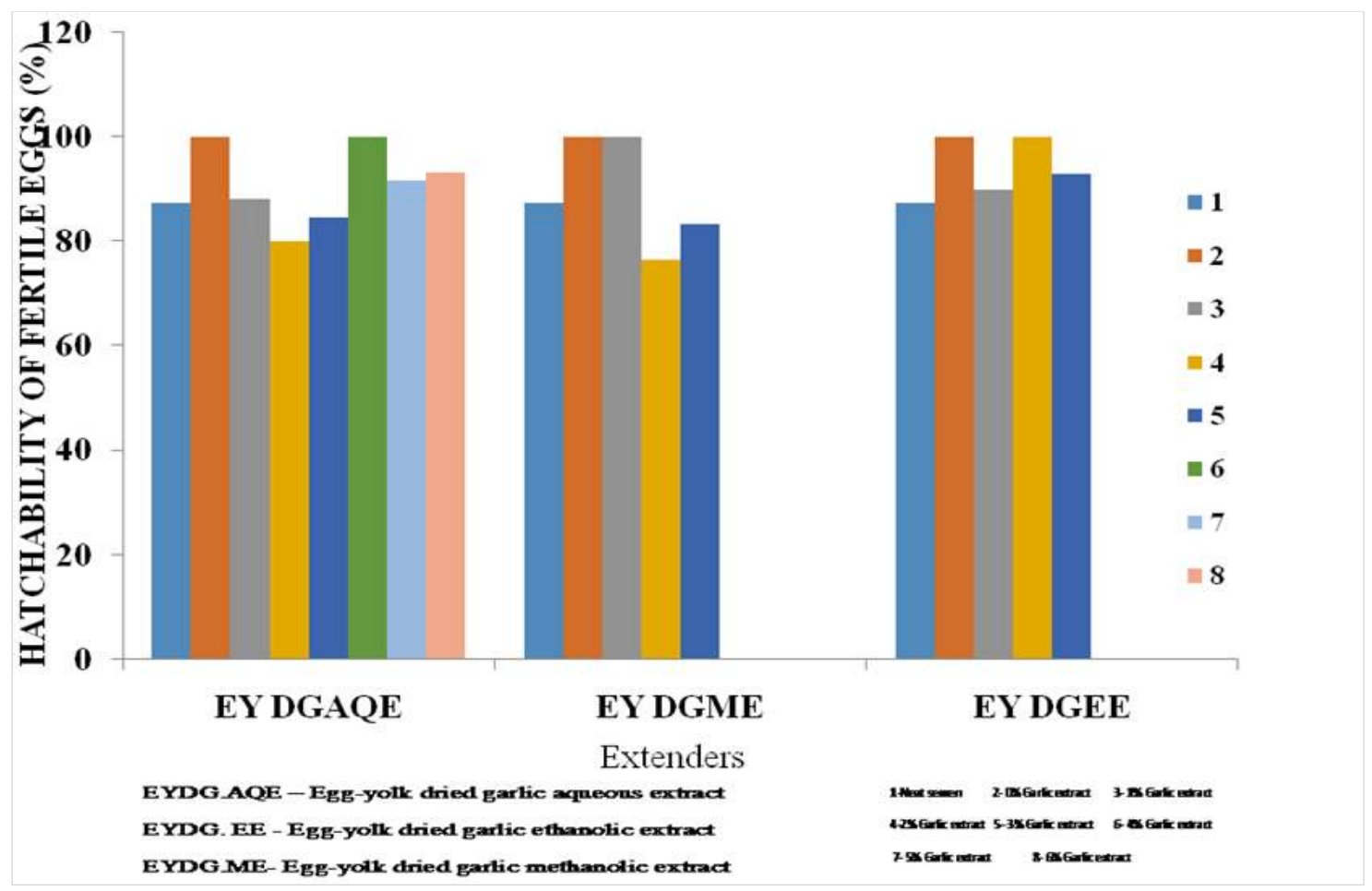

Fig. 6. Effect of dry garlic aqueous, ethanolic and methanolic extracts on inseminated hens hatchability of fertile eggs set

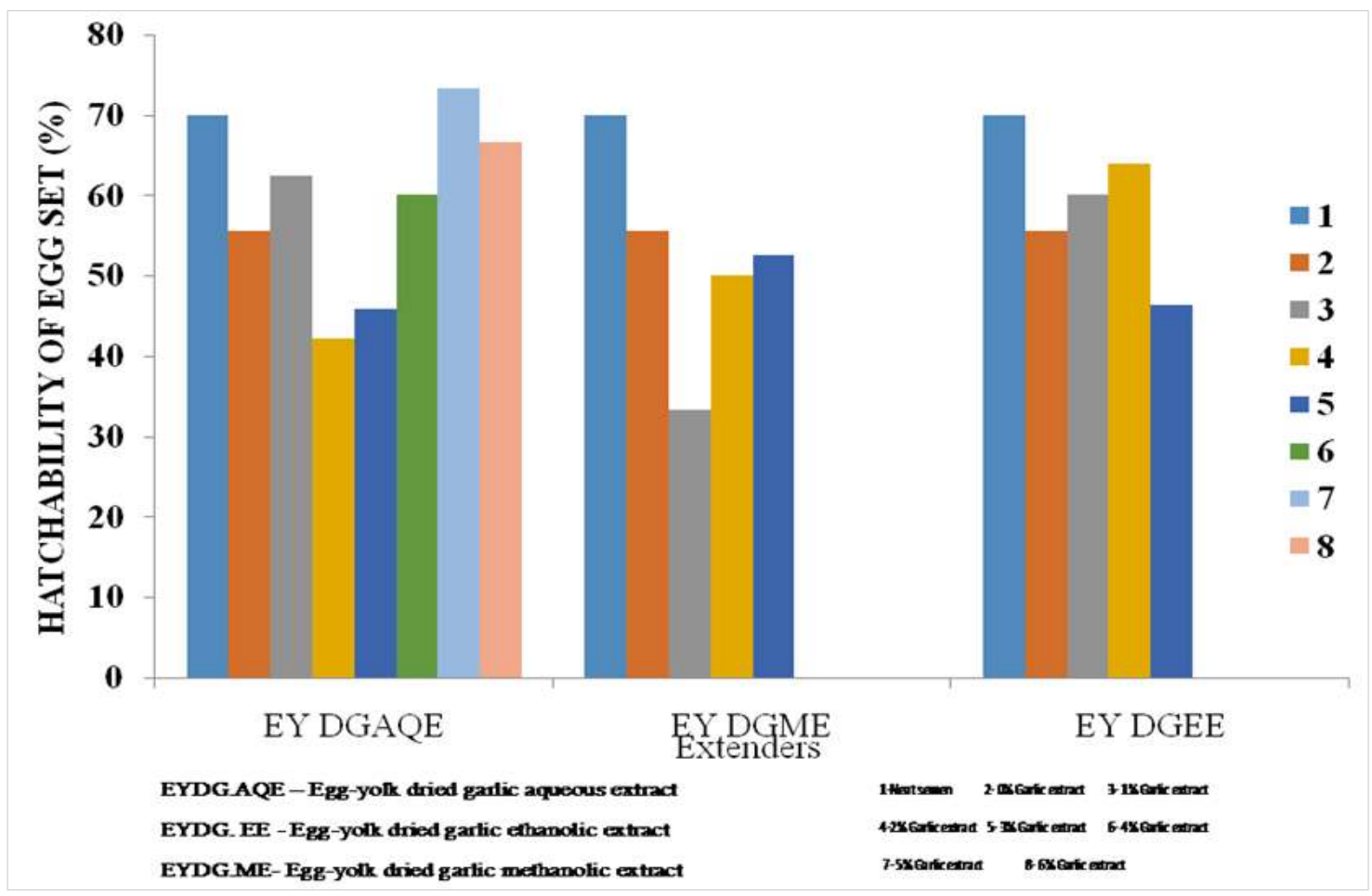

Fig. 7. Effect of dry garlic aqueous, ethanolic and methanolic extracts on inseminated hens hatchability of eggs set 
As a rule of thumb, fertility predetermined hatchability of eggs to a greater extent and this was also positively witnessed in the present experiment across the formulated extenders evaluated for their fertilizing and hatchability capacities.

\section{CONCLUSION}

This study revealed that the three solvents possessed different extraction capability on dry garlic. Dry garlic extracts has a very good free radicals scavenging ability especially when used exogenously with egg-yolk citrate extender for roosters semen dilution. However, a dose dependent and extraction agents influences on garlic extracts is revealed from this study.

Aqueous garlic extract and its antioxidant potential elicited better sperm quality and enhanced in-vivo fertilizing potential of the sperm cells than the other two extracts.

\section{ETHICAL APPROVAL}

The study was approved by the institutional committee on the care and use of animals for experiment, and in accordance with $\mathrm{NIH}$ guide for the care and use of laboratory animals.

\section{COMPETING INTERESTS}

Authors have declared that no competing interests exist.

\section{REFERENCES}

1. Sexton TJ. Review, possible commercial method of freezing chicken semen. Beltsville Agriculture Research Center U.S. Department of Agriculture, Beltsville, Maryland; 1979.

DOI: 10.1002/0471684228.egp11373

2. Kelso KA, Cerolini S, Speake BK, Cavalchini LG, Noble RC. Effects of dietary supplementation with $\alpha$-linolenic acid on the phospjolipid fatty acid composition and quality of spermatozoa in cockerel from 24 to 72 weeks of age. Journal of Reproduction Fertitity. 1997;110:53-59.

3. Al-Daraji HJ. Diluent supplementation with vitamins $A, C$ and $E$ for improving fertilizing ability of indigenous roosters' semen. Patent No. 3195, issued from C. O. S. Q. C., Iraq; 2004.
4. Nuutila AMR, Puupponen-pimia, Aami M, Oksman-Caldentey KM. Comparision of antioxidant activities of onion and garlic extracts by inhibition of lipid peroxidation and radical scavenging activity. Food Chemistry. 2003;81:485-493.

5. Augusti KT, Mathew PT. Effect of allicin on certain enzymes of liver after a short term feeding to normal rats. Experentia. 1975;31:148-149.

6. Miller HE, Rigelhof $F$, Marquart L, Prakash A, Kanfer M. Antioxidant content of whole grain breakfast cereals, fruits and vegetables. Journal of America Coll. Nutrition. 2000;19:1-8.

7. Ohnishi T, Ohnishi T. In vitro effects of aged garlic extract and other nutritional supplements on sickle erythrocytes. Journal of Nutritrition. 2001;131:1085S1092S.

8. Ola-Mudathir KF, Suru SM, Fafunso MA, Obioha UE, Faremi TY. Protective roles of onion and garlic extracts on cadmiuminduced changes in sperm characteristics and testicular oxidative damage in rats. Food and Chemical Toxicology. 2008;46:3604-3611.

9. Trimeche $A$, Anton $M$, Renard $P$, Gandemer G, Tainturier D. Quail egg yolk: A novel cryoprotectant for the freeze preservation of Poitou jackass sperm. Cryobiology. 1997;34:385-393.

10. AOAC. Official methods of analysis, eighteenth revised. Association of Official Analytical Chemists, Arlington, Virginia, USA; 2005.

11. Bursal E, Gülçin İ. Polyphenol contents and in vitro antioxidant activities of lyophilized aqueous extract of kiwifruit (Actinidia deliciosa) Food Res International. 2011;44:1482-1489.

12. Balogun $A S$, Yaqoob $M$, Jimoh $O A$, Poonam A. Antioxidant activity and phytochemical analysis of aqueous garlic extracts. International Quarterly Journal of Life Sciences, The Bioscan. 2016;11:21972199.

13. Xu BJ, Chang SK. A comparative study on phenolic profiles and antioxidant activities of legumes as affected by extraction solvents. Journal of Food Science. 2007;72:S159-166.

14. Munday JS, James KA, Fray LM, Kirkwood SW, Thompson KG. Daily supplementation with aged garlic extract, but not raw garlic, 
protects low density lipoprotein against in vitro oxidation. Atherosclerosis. 1999;143: 399-404.

15. Ryu K, Ide N, Matsuura H, Itakura Y. Na 91- Deoxy-D-fructose-1-yl)-L-Arginine, an antioxidant compound identified in aged garlic extract. Journal of Nutrition. 2001;131:972S-976S.

16. Oi Y, Imafuku M, Shishido C, Kominato $Y$, Nishimura S, Iwai K. Garlic supplementation increases testicular testosterone and decreases plasma corticosterone in rats fed a high protein diet. Journal of Nutrition. 2001;131:21502156.

17. Donoghue, Donoghue. Effects of water and lipid - soluble antioxidants on turkey sperm viability, membrane integrity, and motility during liquid storage. Poultry Science. 1997;76:1440-1445.

18. El-Nasry E, Khalil HM, Abaza M, ElSaadany A. Use of antioxidants in storing local cockerels semen 1. Effects on semen quality and fertility. WPC, XXII World's Poultry Congress, Istanbul, Turkey; 2004.

19. Al-Daraji HJ. Effect of vitamin $E$ on semen quality and fertilizing ability of roosters. Dirasat, Agric Science. 2000;27:360-365.

20. Al-Daraji HJ. Effect of vitamins $A, C$ or $E$ on quality of fowl semen stored for 24 hours at $4^{\circ} \mathrm{C}$. Iraqi Journal of Agricuture. 2002;7:170-181.

21. Ansari MS, Rakha BA, Akhter S. Effect of L-cysteine in extender on post-thaw quality of Sahiwal bull semen. Animal Science Paper Reproduction. 2011;29:197-203.

(c) 2017 Balogun et al.; This is an Open Access article distributed under the terms of the Creative Commons Attribution License (http://creativecommons.org/licenses/by/4.0), which permits unrestricted use, distribution, and reproduction in any medium, provided the original work is properly cited.

Peer-review history:

The peer review history for this paper can be accessed here: http://sciencedomain.org/review-history/19322 